\title{
Imponer el miedo en la política bajomedieval castellana ${ }^{1}$
}

\section{Imposing Fear in Late Medieval Castilian Politics}

\author{
Óscar ViLlaRroel GonZÁLeZ \\ Universidad Complutense de Madrid \\ osvillar@ucm.es
}

\section{RESUMEN}

A lo largo de los siglos XIV y XV el miedo fue presentado en muchas ocasiones en las fuentes, especialmente cronísticas, que nos ha legado el periodo. A lo largo del presente trabajo se pretende analizar cómo se presenta ese miedo y si se utilizó como un arma política, así como cuáles fueron sus principales manifestaciones, las respuestas y las consecuencias que ese miedo provocó.

Palabras clave: Monarquía, Castilla, política del miedo, conflictos, siglos XIV y XV.

\begin{abstract}
Fear was often represented in the sources for Castilian history from the XIVth and XVth centuries. This paper will analyze how fear was presented and whether or not it was used as a political strategy, as well as its principal manifestations, the responses to fear and the consequences that it provoked.
\end{abstract}

Key words: Monarchy, Castile, Fear Politics, Conflicts, XIVth and XV Centuries.

Sumario: 1. El miedo como arma política. 2. El miedo sentido. 3. El miedo impuesto. 3.1. El miedo por las acciones regias. 3.2. Los actos regios de castigo ejemplar y el miedo al rey. 3.3. El miedo inducido como arma política: la falsedad. 3.4. Consecuencias del miedo inducido en la política castellana. 4. Conclusiones.

\footnotetext{
${ }^{1}$ El presente trabajo se enmarca dentro del Proyecto de Investigación del Ministerio de Ciencia e Innovación N N $^{\circ}$ HAR2010-1672, "Prácticas de Consenso y de pacto e Instrumentos de representación en la cultura política castellana (siglos XIII al XV)"
} 


\section{EL MIEDO COMO ARMA POLÍTICA}

El recurso al miedo como arma política es un fenómeno que nada tiene de novedoso, aunque en los tiempos presentes haya habido un profuso uso del mismo en muy diversos sentidos. Esta utilización no es, como digo, nueva, y en periodos tan remotos como la Edad Media podemos encontrar claramente menciones al miedo que algunas decisiones o actuaciones políticas impregnaban en la sociedad o en parte de ella. Sin embargo, si pretendemos analizar el miedo político, tal y como se nos presenta en las fuentes castellanas, hay una serie de preguntas que es necesario responder antes.

Es necesario saber si podemos atender al miedo como un sujeto histórico, es decir, como algo que podamos comprender en un pasado, teniendo en cuenta que existe un condicionante: la propia visión del miedo y de la política que tenemos hoy día. Joanna Bourke ha sido la principal autora que ha trabajado sobre el miedo y su historia. Partiendo de los análisis anteriores de Lutz y Abu-Lughod ${ }^{2}$, para ella el miedo forma parte de las emociones que puede vivir una sociedad, con ello, y por ello, está netamente unida a cada sociedad y, en cierto modo, es indisoluble de la misma ${ }^{3}$. Para los dos primeros autores, el miedo, además, tiene la capacidad de influir en la sociedad y en sí es una forma de acción social ${ }^{4}$. De ahí se extrae que ciertamente el miedo tiene la notable capacidad de su posible utilización con fines políticos, puesto que puede influir en la sociedad y se nutre de sus mismos basamentos. Una utilización para fines políticos que tiene una notable relación con la presencia y la utilización del miedo por los medios de comunicación, por cuanto puede sentir ese miedo cualquiera que reciba información por ese medio. De ahí lo importante que es controlarlos.

Sin embargo, y como adelantábamos, el miedo, como algo social y algo cultural está indisolublemente unido a la sociedad a la que pertenece. A distintas culturas y distintas sociedades nos encontramos distintos miedos y formas de expresarlo ${ }^{5}$. Incluso en el caso de sociedades y culturas semejantes el miedo puede ser muy disímil, sin embargo eso no quiere decir que las manifestaciones sean diferentes. Sociedades muy dispares y alejadas pueden responder de la misma forma al miedo ${ }^{6}$.

Cabe preguntarse, pues, si podemos llegar a conocer el miedo de sociedades del pasado, por ende de la medieval, y en concreto de la castellana bajomedieval. Teóricamente podríamos, conociendo la sociedad y conociendo su cultura; pero la realidad nos dice que nuestra propia sociedad y punto de vista nos puede confundir la realidad de ese miedo. En el fondo si atendiésemos a mostrar ese miedo concreto, estaríamos ante un miedo de nuestra sociedad y época. Es decir, en un sentido lato no podríamos conocer ese miedo. Sin embargo, sí sabríamos, desde luego que tenían miedo y a qué.

${ }^{2}$ L. Abu'Lughod y C.A. Lutz, "Introduction: Emotion, Discourse and the Politics of Everyday Life", en L. Abu'Lughod y C.A. Lutz, (eds.), Language and the Politics of Emotion, Cambridge, 1990, p. 12.

3 J. Bourke, Fear: A Cultural history, Emeryville: Shoemaker, 2006.

${ }^{4}$ L. Abu'Lughod y C.A. Lutz, “Introduction: Emotion, Discourse..., p. 12.

5 J. Bourke, "Fear and Anxiety: Writing about Emotion in Moder History", History Workshop Journal, 55-1 (2003), pp. 111-133, p. 119.

${ }^{6}$ Ibídem, p. 123. 
En cuanto al miedo en la política, que es lo que nos interesa en el presente trabajo, Bourke mostró también cómo "el miedo está relacionado con las relaciones de poder y resistencia"'. El propio juego político está relacionado con el miedo, puesto que es utilizado dentro de él. De esta forma, podemos analizar cómo es utilizado en los distintos modelos de juego político, aunque no podamos llegar a comprender en qué consiste (es decir, qué hacía sentir). De esta forma sí podemos pretender analizar el miedo político y su utilización en el periodo medieval, puesto que nuestro objetivo no sería analizar en qué consiste ese miedo, sino cómo se utiliza, a qué se tiene miedo y las respuestas de tipo político que se consiguen por su mediación. Pero, ¿podemos llegar a conocer el miedo en la política castellana de los siglos XIV y XV? El miedo en sí tal vez no, es decir a qué llamaban miedo en esos momentos. Sin embargo sí podemos saber a qué decían tener miedo, cómo se inspiraba, si era premeditada tal acción. También podríamos, incluso, llegar a conocer cómo se sentía aquél que se veía embargado por el miedo, pues hay descripciones de ello, así como de las consecuencias de tal sensación.

Obviamente, también podemos analizar cómo se utilizó el miedo en los medios de comunicación pasados, pues en ellos, como mostró François Foronda, hay una especial importancia de la plasmación de emociones dentro de la comunicación y la acción política ${ }^{8}$. De hecho, es muy importante analizar en qué momento se está plasmando ese miedo y si responde a una construcción política concreta. Esto comenzó a hacerlo François Foronda de una forma introductora, centrándose en la construcción de unas relaciones políticas determinadas por parte de la monarquía9. Sin embargo, cabe hacer también una aproximación más amplia, es decir, desde el conjunto de la sociedad política. La monarquía utilizó el miedo, pero sin duda la nobleza también lo hizo ${ }^{10}$. Ese análisis más amplio, en un sentido eminentemente utilitario y político, será el que se realice a lo largo del presente análisis, teniendo muy en cuenta las conclusiones que ya apunta el profesor Foronda.

¿Qué objetivos podía tener esa utilización del miedo? Indudablemente dirigir la política, conservar o adquirir el poder... El miedo es, sin duda, uno de los principales fenómenos capaces de forzar una conducta, de ahí que tenga una funcionalidad política bien clara, aunque sea de corto alcance puesto que no consigue, normalmente, la convicción ${ }^{11}$. ¿Qué medios se utilizaron? Será algo que habrá que analizar, pero cabe plantearse si se sembró el miedo o si se eliminaron enemigos. Y por último, una vez apreciado todo esto, podríamos llegar a determinar si se consiguió el objetivo que se buscaba con todo ello: ¿se redirigió la política en un sentido concreto?

${ }^{7}$ Ibídem, p. 129.

${ }^{8}$ F. Foronda, "El miedo al rey. Fuentes y primeras reflexiones acerca de una emoción aristocrática en la Castilla del siglo XIV", e-Spania, 4 (2007) [consultado por última vez el 27 de diciembre de 2012], URL: http:/e-spania.revues.org/2273; DOI: 10.4000/e-spania.2273, § 5 y ss.

9 Así lo ha realizado François Foronda en el trabajo ya indicado en la nota anterior.

${ }^{10}$ El mismo Foronda así lo indicaba (ibídem, § 9), realizando la separación política del espanto/política del miedo. Sin embargo, en las fuentes no aparece diferencia, en ambos casos se habla del "miedo" que fuerza a tomar una decisión o postura. Sin negar la diferencia de base que puede haber entre ambas, me referiré a ellas de la misma forma.

11 Jordi Berrio, Teoría social de la persuasión, Barcelona: Mitre, 1983, p. 96. 
Nuestras fuentes serán obviamente las crónicas, más toda aquella documentación que, versando sobre conflictos o debates de índole político nos manifiesten la situación de los diversos actores que participaban, y en los que se plantee el miedo como una variable que influye en las actuaciones políticas.

Conceptualmente será necesario diferenciar el temor del miedo. Ambas palabras no representan lo mismo, y en el contexto bajomedieval, y en lo relativo al poder, tenían un significado muy distinto, así como una aplicación a la política muy distinta. Los reyes, además de amados, se consideraba que debían ser temidos. Eso no significaba, obviamente, que tuviese que tenerse miedo a los reyes o que estos tuviesen que hacer que todos sus súbditos les tuviesen miedo ${ }^{12}$. Esta distinción ya la tenían clara en el siglo XIII, y así quedaba reflejado en las Partidas ${ }^{13}$, ahí en la segunda partida se define bien el miedo en el sentido político que aquí se tratará: el que nace del "espanto de premia", es decir, de la coacción.

Cuando se analizan las diversas fuentes del periodo podemos ver cómo aparece el miedo reflejado en ellas de formas muy diversas ${ }^{14}$. Básicamente podríamos ver cómo se refleja el miedo que se siente, que sienten los diversos personajes, donde habrá que ver a qué y por qué se tiene miedo o se dice que se tiene miedo. Por otro lado, estaría el miedo impuesto, es decir, cuando no se siente miedo, sino que se intenta sembrar el miedo de forma consciente (aunque también inconsciente en ocasiones). Habrá que verlos por separado, porque uno nos habla de la presencia del miedo (que será interesante conocer previamente) y otro nos habla, en sí, de la política del miedo, de las iniciativas para sembrar el miedo o que tuvieron ese resultado.

\section{EL MIEDO SENTIDO}

El miedo sentido aparece numerosas veces reflejado en las fuentes. En muchas ocasiones a lo largo de los ciclos cronísticos bajomedievales podemos encontrarnos menciones a que tal o cual noble sentía miedo o sintió miedo por alguna razón concreta. En muchas ocasiones aparenta ser una excusa política más, para evitar hacer algo que demandaba el rey, normalmente acudir a su corte, aunque siempre sea difícil diferenciar entre excusa y realidad. Este miedo que los nobles sentían ante el rey era de diversa procedencia. En primer lugar, el más básico y el que aparece indicado más veces, era el miedo a que el rey pudiese atentar contra su integridad física o, directamente, contra su vida. Este tipo de miedo aparece asignado normalmente a la nobleza.

\footnotetext{
${ }^{12}$ Ya mostró la diferencia entre ambos José Luis Bermejo Cabrero, Máximas, principios y símbolos políticos, Madrid: Centro de Estudios Constitucionales, 1986, pp.32-35.

${ }^{13}$ Las Siete Partidas, II, XIII, 15: "et como quier que temor et miedo es naturalmente como una cosa, empero segunt razón departimiento ha entre ellos, ca la tenencia viene de amor, et el miedo nasce de espanto de premia".

${ }^{14}$ Hay dos corpus documentales que considero fundamentales para acceder a estas fuentes y que están ambos fácilmente disponibles. Por un lado el de François Foronda en su "El miedo al rey. Fuentes y primeras reflexiones...", § 27-93; así como el que incluí, al tratar el delito político, en mi "El crimen político en la Baja Edad Media: entre la oposición política y el delito. Segunda parte. Documentos", Clío \& Crimen 8 (2008), pp. 376-689.
} 
Eran las acciones regias, o del poder regio en periodos de minoría, las que actuaban normalmente como detonante de este miedo. Así, durante el reinado de Sancho IV, por ejemplo, nos encontramos con el caso de Diego López de Haro, quien, ante la muerte de su hermano a manos del rey la crónica indica como el noble se encerró en Carmona "con grand miedo que ovo de muerte"15. Del mismo modo, Juan Núñez y el infante Juan son presentados como temerosos del rey cuando éste se volvió contra ellos, lo que hizo que "volviéronse ${ }^{16}$ con grand miedo que ovieron del rrey contra tierra de León". Este miedo no sólo afectaba a la nobleza, sino a todo aquel que pudiese enfrentarse al monarca. Así, la crónica de Pedro I nos indica cómo la reina Blanca de Borbón acudió a la iglesia de Toledo (donde había sido llevada por orden regia) y “desque allá llegó non quiso salir de la Iglesia con miedo que avia de prisión, ó de muerte: é esto fué con consejo del Obispo, é de los que con ella venían"17. Como vemos el juego político tenía mucho que ver, y podía ser utilizado también para mostrar una imagen concreta de los culpables. En este caso, como vemos, se achacaba las culpas de la acción de la reina al obispo y la corte de la reina, que le inculcan el miedo ante las posibles intenciones de Pedro I.

El miedo al rey o sus acciones fue utilizado también para justificar las acciones propias. Y esto no fue exclusivamente achacado a los reyes, sino también a quienes ostentaban el poder regio. Eso sí, siempre para buscar respaldar una actuación propia. Así, el arzobispo Tenorio juró las ordenanzas de Madrid por miedo a las represalias que los miembros del consejo real pudiesen tomar. Esto, normalmente, se hacía constar como forma de justificación. Lo vemos en el caso de Tenorio ${ }^{18}$, pero también muchos años después cuando Pacheco decía que había jurado a Juana, hija de Enrique IV, por miedo al rey ${ }^{19}$.

Qué duda cabe, pues, de que mostraban ese miedo al rey (o al menos decían que lo tenían). Pero, ¿cuáles eran las reacciones que tomaban movidos por ese miedo?

En muchas ocasiones era el pesar lo que se mostraba. Así, cuando los nobles se reúnen con la reina María de Molina en Quintanilla le manifestaron su temor a que el rey les matase, lo cual les causaba una desazón casi vital pues: "nunca tan mal día vieran de andar con miedo e rescelos de su rrey e señor"20. No era la única, obviamente, también en ocasiones hacía que el enfrentamiento con el poder fuese más enconado. Así, Juan Manuel, por ejemplo, se alió con el rey de Granada por ese miedo que decía tener al monarca:

15 Ferrán Sánchez de Valladolid, Crónica de Sancho IV, ed. Cayetano Rosell en Crónicas de los Reyes de Castilla, Biblioteca de Autores Españoles 67, Madrid, 1953, p. 80.

16 Ibídem, p. 87.

17 Pero López de Ayala, Crónica del rey don Pedro primero, ed. Cayetano Rosell en Crónicas de los Reyes de Castilla, vol. I, Biblioteca de Autores Españoles vol. 67, Madrid, 1953, p. 447.

18 Pero López de Ayala, Crónica del rey don Enrique tercero de Castilla e de León, ed. Cayetano Rosell en Crónicas de los Reyes de Castilla, vol. II, Biblioteca de Autores Españoles vol. 68, Madrid, 1953, p. 169.

19 Sección Nobleza del Archivo Histórico Nacional, Frías, 15, 1. En este caso cabe indicar que se trata de una minuta, sin que exista prueba fehaciente de que es de 1462.

${ }^{20}$ Ferrán Sánchez de Valladolid, Crónica del rey don Fernando cuarto, ed. Cayetano Rosell en Crónicas de los Reyes de Castilla, Biblioteca de Autores Españoles 67, Madrid, 1953, p. 157. 
que fuese cierto que ayudaría á él contra el Rey de Castiella cada que le fuese menester, en manera que viese él que era del muy bien ayudado. Et Don Joan, oída esta mandaderia, plógole mucho dello, ca su voluntat tenia puesta en daño et en deservicio del Rey de Castiella en quanto el podiese, como aquel que con miedo del Rey de cada dia rescelaba la muerte ${ }^{21}$

En otras ocasiones se decidían por la huida, como Juan Estébanez, privado de Alfonso XI, huyendo en 1352 de la corte por miedo al rey Pedro ${ }^{22}$. O, simplemente, no acudiendo a las llamadas regias y procediendo a encastillarse en sus propiedades, como el caso de Alfonso de Noreña en Burgos ante la llamada de Enrique III, siempre alegando "gran miedo" que tenían del rey ${ }^{23}$.

Pero el poder regio también fue víctima de los intentos de imposición del miedo. Este nos puede ser transmitido de dos formas. Por un lado el miedo que se intentaba imponer al poder regio, como forma de obtener alguna contrapartida de índole política. Y por otro el miedo que, de forma efectiva, forzaba al rey a llevar a cabo una actuación concreta. En cierto modo, podríamos verlo como el intento y el éxito de la misma acción. Qué duda cabe que es una forma más de utilización o de la presencia del miedo en la política, pero en ocasiones los textos no parecen dudar de la intencionalidad. Para ello obviamente tenían que coincidir una serie de factores: por un lado una monarquía o un monarca debilitado (sin lugar a dudas a lo largo de la Baja Edad Media castellana encontramos numerosas ocasiones en las que esto ocurre). Y unido esto a una nobleza poderosa y ambiciosa, se estaba creando el caldo de cultivo para que ocurriese. ¿Y de qué forma se suele intentar producir miedo a la monarquía? Con las alianzas nobiliarias, es decir, aliándose los más poderosos nobles del reino para amedrentar con su fortaleza al rey. También por medio, directamente, de la mentira.

Así, el infante Fernando de la Cerda, hijo de Alfonso X, recibía un aviso de evitar que le indujesen al miedo algunas palabras de la nobleza, en este caso de una posible invasión norteafricana:

otra parte vos dicen que vos non tenedes aver que les dar, é yo que non he con qué vos acorra. É diciéndovos las cosas falsamente desta guisa, meton vos miedo por cuidar vos traer á facer lo peor; porque ha menester que paredes ý mientes que si agora en vuestro comienzo en estas cosas errades, después cuando las quisiéredes emendar non podredes ${ }^{24}$

Con ello, como vemos, se recurría a una hipótesis sin fundamento aparente, pero que sí tenía un notable peso simbólico. No sería la única vez que la nobleza no dudase en amenazar a la monarquía. Años después, el problemático reinado de Sancho IV por la cuestión de la legitimidad, Lope Díaz de Haro III era visto por el resto de la nobleza como aquel que mejor era capaz de plegar al monarca a sus deseos por me-

${ }^{21}$ Ferrán Sánchez de Valladolid, Crónica del rey don Alfonso el onceno, ed. Cayetano Rosell en Crónicas de los Reyes de Castilla, Biblioteca de Autores Españoles 67, Madrid, 1953, p. 233.

22 Pero López de Ayala, Crónica del rey don Pedro primero, p. 427.

${ }_{23}$ Pero López de Ayala, Crónica del rey don Enrique tercero, p. 231.

${ }^{24}$ Ferrán Sánchez de Valladolid, Crónica de Alfonso X, ed. Cayetano Rosell en Crónicas de los Reyes de Castilla, Biblioteca de Autores Españoles 67, Madrid, 1953, p, 40 
dio de la utilización del miedo. De esto fue consciente el propio monarca tras recibir consejo del rey de Portugal:

é él que entendía ya cuan mal recabdo ficiera en apoderar tanto al Conde, é porque se fallaba él desapoderado, que le rogaba é mandaba que sobre este fecho que le enviase consejar commo ficiese. É el obispo [de Astorga], cuando esta mandaderia ovo del Rey, plúgole mucho, lo uno porque el Rey quería cobrar el poder de los sus reinos, é lo otro por salir del miedo é recelo del Conde en que estaba ${ }^{25}$

En este caso nos encontramos con esa utilización del miedo por parte de la nobleza. Años después ocurrió lo mismo durante la minoría del rey Fernando IV, cuando la reina María de Molina tuvo que hacer frente a las acciones del infante Enrique el Senador. La tutora tuvo que ponerse de acuerdo con el infante para ser tutor, el único de hecho, y la crónica indica que "gelo otorgase con miedo" debido a la alianza que había llevado a cabo con el infante Juan y con Juan Núñez ${ }^{26}$.

Pero las personas que ostentaban el poder regio también podían llegar a sentir un miedo de tipo político de forma real. Como hemos podido ver en el caso anterior, hubo ocasiones en que ese intento de sembrar el miedo en el poder regio con unos objetivos políticos alcanzó el éxito. Las crónicas también nos lo presentan, no ya como una visión exterior (como en el caso ya comentado de Sancho IV), sino directamente como una apreciación del monarca.

Obviamente no siempre el miedo se debió a una acción concreta de la nobleza, también podía darse por un recelo debido a la situación política imperante en el reino (aunque la posición o actuación nobiliaria tuviese parte en ello). El mejor ejemplo lo encontramos al final del reinado de Alfonso X. Hubo un momento, tras la sublevación nobiliaria y la oferta del trono a Sancho IV, en que corrió el rumor por el reino que el infante había muerto. Cuando la noticia llegó al rey, a decir de la crónica, este tuvo miedo a que eso le hiciese perder el reino por no haber logrado alcanzar un acuerdo con su hijo. El miedo del rey en esta ocasión se debía al miedo que en el reino se podía tener de él mismo: "el miedo que tomaron de mi los de las mis villas e todos los ricos omes e las órdenes por el yerro que me ficieron" ${ }^{27}$. El miedo juega un papel doble en este caso.

Pocos años después, pero en el reinado del nieto de Alfonso, Enrique el Senador, tutor en esos momentos de Fernando IV, también fue mostrado como obligado a cambiar su política víctima del miedo a perder el poder. Así, se vio forzado a abandonar la frontera de Granada, tras acordar una tregua con el rey zirí porque "ovo muy grand miedo que le tirarían la guarda de los reinos, porque él avía desamparado al rey"28.

\footnotetext{
${ }^{25}$ Ferrán Sánchez de Valladolid, Crónica de Sancho IV, p. 77.

${ }^{26}$ Ferrán Sánchez de Valladolid, Crónica del rey don Fernando cuarto, p. 122.

27 Ferrán Sánchez de Valladolid, Crónica de Alfonso X, p. 65

${ }^{28}$ Ferrán Sánchez de Valladolid, Crónica del rey don Fernando cuarto, p. 106.
} 


\section{EL MIEDO IMPUESTO}

Como puede observarse, las fuentes nos mencionan en muchas ocasiones el sentimiento del miedo como una realidad, que era causado por unas situaciones políticas específicas, y que hacía que se tomasen unas decisiones concretas. Habrá que ver si el miedo fue algo que se impusiese de forma premeditada para conseguir esas reacciones. Es decir, ¿hubo políticas o actuaciones políticas dirigidas directamente a sembrar el miedo entre los contendientes como forma de conseguir una actuación concreta e interesada? Parece plausible decir que sí a la vista de los casos anteriores, sin embargo nos interesa especialmente analizar si hubo acciones regias que utilizasen el miedo como arma, así como si otros utilizaron el miedo al poder regio como una forma de obtener réditos políticos.

\subsection{EL MIEDO POR LAS ACCIONES REGIAS}

Qué duda cabe que el miedo provocado por las acciones regias entra dentro de la definición de una política del miedo. El poder regio, en un momento en el que estaba construyéndose como el único del reino y como la cabeza de un Estado, parece el más adecuado para imponer una política del miedo contra sus rivales, especialmente cuando efectivamente había rivales que no dudaban en oponerse al monarca de forma abierta. Esa contestación al poder debía ser eliminada y reducida de una forma ejemplar, incluso, algo que, efectivamente, veremos que ocurrió en ocasiones.

El miedo, en ocasiones, fue un resultado secundario de otro objetivo regio: eliminar a un rival político. En un siglo tan convulso políticamente como el siglo XIV, hubo numerosos nobles, procedentes de la familia real o no, que no dudaron en levantarse contra el rey o actuar políticamente contra sus intereses de forma casi continua. Para algunos monarcas eliminar esas resistencias era vital, y en más de una ocasión no encontraron (o no supieron encontrar) una forma mejor que su eliminación: es decir, recurrir al asesinato, al crimen político ${ }^{29}$. Aquí el miedo aparece en dos niveles de nuevo. Por un lado el miedo que en ocasiones los objetivos de la venganza regia decían sentir; por otro el miedo que con su muerte podría imponerse al resto de la nobleza.

Este tipo de actuaciones regias fueron, en ocasiones, muy habituales. Así, Fernando IV intentó en más de una ocasión eliminar al infante Juan. Por ejemplo, le tendió una celada en Burgos. Allí intento concertar una reunión con el infante en la ciudad, como forma de poder prenderle y acabar con su vida. La reunión, por así decirlo, era una trampa para poder acabar con él. En ese momento encontramos el miedo que decía sentir el infante, sin duda como fruto de su oposición al monarca. Este miedo hizo que no se atreviese a entrar en Burgos, al decir de la crónica porque "recelábase mucho de entrar en la villa, que avía miedo del rrey muy grande de muerte" ${ }^{30}$. Como

${ }^{29}$ Sobre el crimen político y el recurso al asesinato como forma de eliminar a los rivales véase: Óscar Villarroel González, "El crimen político en la Baja Edad Media: entre la oposición política y el delito. Primera parte. Estudio", Clio y Crimen, 5 (2008), pp. 267-374, en concreto, para la monarquía como fuente de estos delitos: pp. 295-305.

${ }^{30}$ Ferrán Sánchez de Valladolid, Crónica del rey don Fernando cuarto, p.165. 
vemos no iba muy desencaminado. El rey intentaría aprovecharse de la figura de la reina María para atraer al infante, traicionando a su misma madre, pero esta fue avisada y para salvar su honor avisó al infante, que huyó ${ }^{31}$. Una de las formas más sencillas de imponer el miedo en los rivales políticos era conseguir la muerte de alguno de ellos.

No fue la única vez que intentó algo así Fernando IV, también lo intentó con Juan Manuel, y de nuevo aprovechando una entrevista concertada entre ambos. En esta ocasión el noble también fue avisado y logró huir ${ }^{32}$. Como vemos Fernando IV lo intentó en un par de ocasiones pero no logró nada. Aquellos que le sucedieron en el ejercicio del poder regio (bien como reyes o como tutores) y que utilizaron esta misma técnica, fueron mucho más efectivos.

El mismo infante Juan que fue objetivo de la ira regia empleó la misma técnica una vez que se vio con el poder regio en sus manos al desempeñar la regencia. En su caso, él se reunió con García de Villamayor, Juan Rodríguez de Rojas y Juan Martínez de Leyva, que, siendo partidarios del infante Felipe podían suponer un problema a su regencia. En esa reunión fueron muertos los dos primeros y el tercero fue sometido a prisión ${ }^{33}$. Y con ello se consiguió el objetivo propuesto pues "todos los ricos omes et caballeros e otros fijosdalgo del regno tomaron grand miedo de don Joan, et resceláronse mucho dél" ${ }^{34}$.

El mismo Alfonso XI, ya durante su reinado personal, utilizaría el asesinato político como vía de solución de conflictos de esa índole. Así, en 1324 mandó matar a Juan el Tuerto en Toro, junto a dos caballeros que iban con é ${ }^{35}$. Tiempo después, en 1327, haría lo propio con Alvar Núñez, siendo muerto por orden regia por Ramiro Flórez de Guzmán ${ }^{36}$.

Pedro I fue, posiblemente, el monarca bajomedieval que en más ocasiones utilizó esta expeditiva vía para eliminar a sus rivales. Esto, que obviamente se plasmó en una posición nobiliaria bien conocida, influyó en la posteridad en la forma en que fue llamado: el Cruel, lo que es muestra del miedo que despertó entre la nobleza. Este monarca hizo una utilización realmente recurrente de este tipo de actos. Así, en 1356 hizo matar a diversos caballeros de la reina María ante ella en Toro ${ }^{37}$. En 1366 hizo lo propio con Suero García de Toledo, arzobispo compostelano, y con el deán Pedro Álvarez de Toledo ${ }^{38}$. Juan Alfonso de Benavides, justicia mayor, y que en diversas ocasiones participó en este tipo de acciones por orden regia, murió el mismo por orden de Pedro en Almodóvar del Río, donde le llevó preso desde Sevilla en $1365^{39}$.

\footnotetext{
${ }^{31}$ Ibídem.

32 Andrés Giménez Soler, Don Juan Manuel. Biografia y estudio crítico, La Academia, Zaragoza, 1932 , documento $n^{\circ}$ LXXXIV, pp. 292-293, lo incluí en mi "El crimen político en la Baja Edad Media en Castilla: entre la oposición política y el delito. Segunda parte. Documentos", Clío y Crimen, 5 (2008), p. 464, doc. 79.

33 Ferrán Sánchez de Valladolid, Crónica del rrey don Alfonso el onceno, p. 193.

34 Ibídem.

35 Ibídem, pp. 202-203.

36 Ibídem, p. 219.

37 Pedro López de Ayala, Crónica del rey don Pedro primero, p. 471.

38 Pedro López de Ayala, Crónica del rrey don Pedro y del rrey don Enrique su hermano, hijos del rrey don Alonso el onceno, ed. Germán de Orduna, Buenos Aires, 1994, vol. II, pp. 138-139.

39 Ibídem, pp. 114-115.
} 
Juan Núñez, maestre de Calatrava, también fue muerto por orden regia pese a que éste le había asegurado que no le haría nada ${ }^{40}$. Conocida también es la muerte de Fadrique, maestre de Santiago y hermano del rey Pedro I, que fue asesinado por orden regia en su propia presencia ${ }^{41}$.

Enrique II, monarca que se presentaba como el contrapunto de su hermano Pedro, también llevó a cabo este tipo de acciones. Así, en 1371 el rey dio seguro a Martín López de Córdoba, que estaba en Carmona defendiendo la legitimidad de los sucesores de Pedro I. El rey, sin embargo, le mandó prender y llevar a Sevilla, donde le hizo matar ${ }^{42}$.

Este tipo de acciones, de por sí, suponían posiblemente, o al menos a tenor de lo que las mismas crónicas nos transmiten, una honda impresión en el conjunto de la nobleza, que pasaba a tener miedo de que el rey hiciese lo mismo con ellos. Pero además, en muchas ocasiones este tipo de actos fueron acompañados, o seguidos, de otros que tenían una clara función propagandística para el poder regio. El rey buscaba con ello mostrar su poder y su capacidad de justicia, pero con ello se propagaba también la acción que había cometido y, con ello, el miedo al rey.

\subsection{LOS ACTOS REGIOS DE CASTIGO EJEMPLAR Y EL MIEDO AL REY}

Este tipo de actos eran de índole muy variada. En general podemos ver cómo en diversas ocasiones la monarquía recurrió a diversos tipos de ceremonias como forma de lograr la obtención de un mayor efecto a alguna de sus acciones contra miembros especialmente revoltosos de la nobleza. Es decir, podemos localizar en ocasiones auténticos actos propagandísticos en el entorno de estas actuaciones regias ${ }^{43}$. En ocasiones iban unidas o eran continuación de la eliminación física del rebelde, lo cual nos muestra claramente que su funcionalidad era puramente propagandística (además de una posible búsqueda de legitimación de la muerte que el rey había ordenado). Para ello normalmente se recurría a la utilización de la legislación que había en lo tocante a la traición, pues era el motivo que se solía alegar, envolviendo todo de una parafernalia puramente judicial, como veremos.

Así, durante el reinado de Alfonso XI nos encontramos diversas actuaciones de este tipo, en la que se procedió a juzgar a algún noble y a aplicarle la pena correspondiente. Todo ello se dotaba de una forma claramente ejemplarizante y pública, de ahí ese marcado cariz propagandístico. El primero de ellos lo encontramos en 1324. Ese año, tras diversas actuaciones contra el poder regio por parte de Juan el Tuerto, éste decidió finalmente matarle, como ya hemos visto. Una vez muerto el rey ordenó que se hiciese un acto público. Él se asentó en un estrado cubierto de negro y se proclamaron todos los males que el noble había realizado contra el rey: deservicios al rey,

${ }^{40}$ Antes fue sometido a prisión y depuesto del maestrazgo de Calatrava: Pedro López de Ayala, Crónica del rey don Pedro primero, p. 440.

${ }^{41}$ Pedro López de Ayala, Crónica del rrey don Pedro y del rrey don Enrique su hermano, pp. 268-272.

42 Pedro López de Ayala, Crónica del rrey don Enrique segundo de Castilla, ed. Cayetano Rosell en Crónicas de los Reyes de Castilla, vol. II, Biblioteca de Autores Españoles vol. 68, Madrid, 1953, p. 8.

43 Sobre la utilización de la propaganda en el contexto de la violencia política véase: Óscar Villarroel González, "El crimen político...Primera parte", p. 359 y ss. 
intentos de desheredarle, acuerdos con los reyes de Aragón y Portugal contra su propio monarca... Por todo ello determinó que había caído en traición y lo juzgó como ta $l^{44}$. Como vemos, una vez muerto, se realiza el juicio al noble y se le acusa del más grave de los delitos políticos: traición. Con ello se estaba legitimando la acción regia, pero qué duda cabe también se estaba mostrando todo de una forma eminentemente propagandística, se buscaba propagar la acción regia de una forma claramente ejemplarizante. El entorno, además, nos lo muestra: realización de un estrado para hacerlo todo más visible, utilización del color negro, la presencia del rey, la sentencia... ${ }^{45}$

Parecido es el caso de Alvar Núñez, este fue asesinado por orden regia, como se ha comentado ya, en 1327. En este caso nos encontramos de nuevo con toda una ritualización posterior que tenía un marcado objetivo propagandístico. En concreto el rey hizo llevar el cadáver ante él a Tordehumos. Allí se hizo un estrado en el que se situó el trono regio. A continuación el mismo monarca hizo relación de cómo había confiado en el finado Alvar Núñez, y que le había dado gran estado y hacienda en sus reinos. Sin embargo, pese a ello, el noble le había hecho "muchos desconocimientos et gran maldad", si sólo con esto no bastaba, se añadía que por ello el rey había pedido la devolución que los bienes que le había entregado, pero que él se había negado. Por ello le acusaba de traición ("e por esto que cayera en caso de trayción") y como tal fue juzgado. Después le mandó quemar y que todos sus bienes fuesen expropiados ${ }^{46}$. Como vemos, se realiza todo un juicio después de la muerte, se juzga al cadáver que después sufre la pena.

En el caso de Juan Alfonso de Haro nos encontramos una actuación semejante en algunos aspectos. Si bien las fuentes no nos hablan de juicio, sí vemos que se siguió un desarrollo parecido, una vez que el rey llegó a Agoncillo donde estaba refugiado el noble. En efecto el rey hizo llamar a Juan Alfonso, hizo que se le leyesen los delitos de los que se le acusaba, y luego lo mandó matar ${ }^{47}$. Como vemos, se sigue el formalismo de un juicio, actuando el rey, cabeza de la justicia, como juez.

Este tipo de actuaciones no quedaron en el siglo XIV: Juan II en más de una ocasión recurrió también a realizar juicios en los que se dirimían delitos que tenían un cariz eminentemente político. $\mathrm{Y}$ en estos juicios vemos un marcado cariz propagandístico. A Fernán Alfonso de Robres se le encarceló, juzgó y sentenció, igual que a Sancho

${ }^{44}$ Ferrán Sánchez de Valladolid, Crónica del rrey don Alfonso el onceno, pp. 202-203.

45 No es necesario ya hablar sobre la importancia propagandística de las ceremonias, así como de todos los recursos que en éstas se ponían a disposición del mensaje a transmitir, pues la historiografía los ha tratado profusamente. Mencionaré exclusivamente un clásico para el caso castellano, José Manuel Nieto Soria, Ceremonias de la realeza. Propaganda y legitimación en la Castilla Trastámara, Madrid: Nerea, 1993 o un trabajo más reciente y centrado en un solo reinado: Ana Isabel Carrasco Manchado, "Isabel la Católica y las ceremonias de la monarquía: las fuentes historiográficas", e-Spania, 1 (2006), URL: http://e-spania.revues. org/308 ; DOI: 10.4000/e-spania.308 [consultada por última vez el 28 de diciembre de 2012],u otro mío específico sobre las ceremonias de deposición: Óscar Villarroel González, "La escenificación de la ruptura: las deposiciones y sus ritos en la Castilla bajomedieval (siglos XIII-XV)", en J.M. Nieto Soria (dir.), El conflicto en escenas. La pugna política como representación en la Castilla bajomedieval, Madrid: Sílex ediciones, 2010, pp. 211-246.

46 Ferrán Sánchez de Valladolid, Crónica del rrey don Alfonso el onceno, p. 219.

47 Ibídem, p. 263; Gran crónica de Alfonso XI, ed. Diego Catalán, Madrid: Gredos, 1977, pp. 88-89. 
Fernández de León ${ }^{48}$. En el caso de ambos podemos ver que las cuestiones políticas estaban en el fondo de la cuestión. Aunque se les acusasen de delitos de índole política (ambos desarrollaron sus funciones al cargo de las cuentas regias), su participación en el bando opuesto al condestable Luna estaba en la base de su caída en desgracia. Apenas tenemos datos de cómo se llevó a cabo el proceso, pero no nos cabe duda de que éste se hizo según el aparato de justicia y las normas establecidas ${ }^{49}$. En el caso de Fernán Alfonso de Robres, fue apresado por orden regia y tras ser acusado se le sometió a prisión en Uceda, donde moriría tres años despué ${ }^{50}$. Y en el caso de Sancho Fernández de León, sabemos que murió ejecutado en la plaza de la carnicería en Burgos en mayo de 1430, sobre un "tapete" ${ }^{51}$. En este caso el acto propagandístico es manifiesto, más aún si vemos que tal acto fue acompañado de un pregón:

¡Esta es la justicia que manda facer nuestro señor el rey a este ome, que cometió e fizo e puso en obra muchos malefiçios en su ofiçio, fiándolo el rey dél! ${ }^{52}$

Sin duda el carácter ejemplarizante es manifiesto, y más aún al utilizar el pregón. De esta forma se estaba construyendo o intentando construir una opinión concreta sobre la cuestión ${ }^{53}$, en la que el matiz político es fundamental. Los pregones de justicia, de hecho, fueron una característica del ejercicio de la pena capital durante la Baja Edad Media castellana ${ }^{54}$.

El caso del condestable Dávalos es, tal vez, del que tenemos más información, y gracias a ello podemos saber que estamos realmente ante un juicio de marcado cariz político $^{55}$. La acusación se realiza por cuestiones puramente políticas (participación en el Golpe de Tordesillas, participar en el cerco al rey en Montalbán, acudir armado contra la Corte junto al infante Enrique y colaborar con éste en la toma violenta del marquesado de Villena ${ }^{56}$. Se le condenó a la expropiación de todos sus bienes y el rey se reservó emitir la condena corporal (pues estaba huido el condestable) ${ }^{57}$. En este caso la sentencia fue leída en la corte, y no parece que se ordenase su pregón (al menos no consta en el texto de la misma), sin embargo qué duda cabe que la corte era un

48 Pero Carrillo de Huete, Crónica del halconero de Juan II, ed. Juan de Mata Carriazo y Arroquia, Madrid: Espasa, 1946, pp. 329-330.

49 La crónica indica que "so color de justicia", indicando claramente que no era más que una fachada para ocultar otro tipo de intenciones por parte del condestable.

50 Véase, por ejemplo, en Fernán Pérez de Guzmán, Generaciones y semblanzas, en el vol. II de las Crónicas de los Reyes de Castilla, Biblioteca de Autores Españoles 68, Madrid: Espasa, 1953, p. 711.

${ }^{51}$ ¿Acaso sobre un estrado cubierto? Da toda la sensación. Una de las definiciones de la RAE indica que con él se cubre una mesa u otros muebles.

52 Pero Carrillo de Huete, Crónica del halconero..., p. 62.

${ }^{53}$ Véase lo dicho al respecto, sobre opinión pública y el pregón regio, por José Manuel Nieto Soria, "El pregón real en la vida política de la Castilla Trastámara”, Edad Media: revista de Historia, 13 (2012), pp. 77102, en concreto pp. 80-81.

54 Ibídem, p. 92.

55 Véase el estudio de Yolanda Guerrero Navarrete, Proceso y sentencia contra Ruy López Dávalos, condestable de Castilla, Jaén: Instituto de Estudios Giennenses, 1982.

${ }^{56}$ Ibídem, p. 29. Citando Biblioteca de la Real Academia de la Historia, colección Salazar y Castro, N-5, ff. $3 \mathrm{rv}$

57 Ibídem, p. 106. 
medio en el que los interesados podían enterarse bien: todos aquellos con pretensión, ambiciones o intenciones políticas.

\subsection{EL MIEDO INDUCIDO COMO ARMA POLÍTICA: LA FALSEDAD}

El mejor ejemplo que podemos encontrar de que el miedo jugó un papel muy importante en la política bajomedieval castellana es su utilización, qué duda cabe. Esto, sin embargo, puede parecer muy difícil de demostrar. Es decir, ¿acaso sembrar el miedo era el objetivo de los actos comentados en el apartado anterior? La lógica nos puede decir que sí, pero obviamente no podemos demostrar a ciencia cierta si era o no un objetivo de los monarca en el momento de llevarlos a cabo. Pero hay otro tipo de actos que nos muestran claramente cómo el miedo podía ser utilizado para obtener una respuesta política. A lo largo del periodo bajomedieval podemos observar cómo en numerosas ocasiones se recurrió a la mentira para despertar el miedo en algunos personajes, el miedo al rey en concreto. La mentira, incluso, llegó a ser una muy útil arma para inculcar el miedo en los rivales políticos ${ }^{58}$. La esfera de la política se asienta sobre opiniones y creencias compartidas de forma intersubjetiva, de ahí que la alteración de las mismas afecta claramente a la apreciación del mismo, y parece obvio señalar que a su desarrollo ${ }^{59}$. Las consecuencias de ello, en muchas ocasiones, fue la ruptura de negociaciones, cuando no la apertura de hostilidades. ¿Qué tipo de mentiras? Como veremos, se recurrió a hacer llegar noticias falsas o tergiversadas a alguno de los actores principales de la política del reino. En ellas se indicaba que el rey pretendía su muerte, o que iba a ser prendido, o que pretendía arrebatarle sus bienes, o que, simplemente, estaba descontento con él. Con ello se conseguía imponer el miedo en el receptor de tales mensajes, que pasaba a huir del rey cuando no a enfrentarse abiertamente a él como forma de defensa. El miedo no es el objetivo en esta ocasión, sino el medio utilizado para conseguir una respuesta política concreta.

Este tipo de actuaciones nos las encontramos de forma reiterada, como digo, a lo largo de todo el periodo bajomedieval ${ }^{60}$, en situaciones políticas muy diversas pero en las cuales hay algún rasgo en común, como una cierta inestabilidad política con resistencias parciales, cuando no abiertas, al rey, pero que aún no ha llegado a la ruptura, y que cuando ésta se había producido, no era definitiva aún o buscaba solucionarse pacíficamente.

Así, durante el reinado de Sancho IV, las relaciones entre éste y Juan Núñez fueron víctima de este tipo de actuaciones en más de una ocasión. Así, en 1291, estando la corte en Toledo un caballero, Nuño González de Churruchano le avisó de la intención del rey:

Don Juan Núñez ¿qué estades aquí faciendo? Ca yo vi anoche meter muchas armas en casa del Rey, é mandaba armar los caballeros porque viniesen á matarvos

${ }^{58}$ Óscar Villarroel González, "El crimen político...Primera parte”, p. 308.

${ }^{59}$ Marco Estrada Saavedra, "Reflexiones en torno a la mentira y la política", Estudios sociológicos, 22 (1965), pp. 461-481, en concreto p. 465.

${ }^{60}$ Pueden verse diversos ejemplos en: Óscar Villarroel González, "El crimen político...Primera parte", pp. 299, 304, 326 y especialmente 308-312. 
Esto obviamente indujo el miedo en el noble, que intentó abandonar Toledo (aunque las puertas ya estaban cerradas al ser de noche. Hasta el amanecer no pudo reunirse con sus caballeros "e toda la noche ovo de estar con muy gran miedo que nunca durmió" ${ }^{61}$. Sin embargo todo resultó ser mentira, el rey se lo aseguró y, además, humilló públicamente a Nuño González, que abandonó para siempre la corte. Parece evidente que la mentira tenía un claro objetivo político aquí, y que el miedo era el objetivo de la mentira y el medio para conseguir un alejamiento entre el noble y el monarca. Lo que no nos informa, o no nos permite averiguar a primera vista, la crónica es quién fue el promotor de todo ello, pero no era la primera vez. La crónica indica que los mismos caballeros de Juan Núñez, a la mañana, opinaban:

que pues tan gran tiempo avíe que gelo avíen dicho, que cuidaban que non era si non falsedad, por lo arredrar del rey, como ficieron la otra vez

Y el mismo rey juzgaba que "todo esto era por gelo facer perder, commo la otra vegada" 62 .

A la muerte de Sancho IV de nuevo veremos la utilización de la mentira para sembrar el miedo y conseguir un rédito político. El infante Enrique el Senador, hermano de Alfonso X, aspiraba a compartir, por lo menos, la regencia, y para ello no dudó en maniobrar e intentar enfrentar a cuantos más grupos mejor con la reina viuda y tutora, María de Molina. Así, pocos meses después de la muerte de Sancho IV, en 1295, el infante intentaba ganar partidarios en las ciudades castellanas. Cuando la reina ordenó reunir Cortes para poner fin a esa campaña, y al ver el infante que los concejos se aprestaban a acudir al llamamiento de la regente:

quisiéralo partir con los de la tierra que non viniesen a las Cortes, e non pudo, e desque vio que los non pudo partir, metioles miedo, e díjoles que él sabía por cierto que la reina traía ý a don Diego e a don Juan Núñez a don Nuño González, e a todos los ricos omes e a los maestres consigo, e que les quería echar muchos pechos ${ }^{63}$.

El objetivo del infante tenía un claro objetivo: conseguir la disensión dentro del reino y que las ciudades se opusiesen a la regente, para con ello obtener él mismo un rédito político. Es decir, el miedo se utilizaba de nuevo como arma política.

Ya durante el reinado efectivo de Fernando IV lo veremos utilizado de nuevo diversas veces. En 1307, estando el rey ante Tordehumos, donde tenía cercado a Juan Núñez, Pedro Ponce de León abandonó una noche el rey y se introdujo en Lerma. El monarca le envío preguntar a Ponce de León el motivo de su marcha, y este:

enviole decir que se non fuera si non con grand miedo de muerte, que le dijeron que lo quería él prender, e dijo que gelo dijera el infante don Juan ${ }^{64}$.

\footnotetext{
${ }^{61}$ Ferrán Sánchez de Valladolid, Crónica del rey don Sancho IV, p. 84.

${ }^{62}$ Ibídem.

${ }^{63}$ Ferrán Sánchez de Valladolid, Crónica del rey don Fernando IV, p. 94.

${ }^{64}$ Ibídem, p. 155.
} 
De nuevo el objetivo era conseguir la disensión política, conseguir un vacío en torno al rey para ampliar aún más el poder del otro bando nobiliario. Y el miedo de nuevo el medio.

El reinado de Alfonso XI fue muy prolífico en este tipo de actuaciones. Sin lugar a dudas las alteraciones políticas ayudaban a ello, pues era más fácil que la mentira surtiese sus efectos cuando había rencillas y enfrentamientos previos de por medio. En ocasiones simplemente hay menciones a la intención de romper las relaciones pacíficas entre el rey y la nobleza, como Juan Manuel. Alvar Núñez, que se podía ver desplazado por el acercamiento de ambos, "fizo cuanto pudo" para evitar tal cercanía $^{65}$. Y la mentira, en estas actuaciones, tenía también cabida, siendo el miedo, normalmente, el resultado y el catalizador de los cambios que se sucederían.

Así, Fernán Rodríguez, prior de la orden de San Juan, actuó también para evitar un acuerdo entre el rey y Juan Manuel que podía perjudicarle o reducir su capacidad de intervención en el reino. Para ello no dudó en escribir al noble e indicarle que en las vistas que iba a tener con el rey en 1327 "que en esta vista que el rey quería aver con él que lo coydaba matar, et esto que venía por consejo de Joán Martínez de Leyva" ${ }^{66}$. El objetivo era conseguir que el noble no llegase a un acuerdo con el rey, y el miedo de nuevo fue el medio.

Este Juan Martínez de Leyva, que llegó a ser considerado privado de Alfonso XI, actuó de la misma forma cuando vio peligrar su ascendiente sobre el rey al ir este a sellar la paz con Juan Manuel y Juan Núñez. Así, en 1331, durante las vistas de Villumbrales, no dudó en hablar la noche previa al acuerdo con Juan Núñez

E díxole que si él et don Joán, fijo del infante don Manuel, fuesen comer con el rey en Villumbrales que fuesen ciertos que el rey tenía acordado de los mandar matar, et que decía et afrontaba a don Joán Núñez que non quisiese entrar en logar cercado con el rey, nin fuese comer aquella yantar, si non, que fuese cierto que amos a dos don Joán et don Joán, eran muertos ${ }^{67}$.

El dicho Juan Núñez acudió junto a Juan Manuel y le informó de todo ello, motivo por el cual decidieron no reunirse con el rey, lo que tuvo como consecuencia la persistencia de su enfrentamiento con Alfonso y, por ello, la privanza de Martínez de Leyva. El objetivo de éste estaba claro, mantener su privanza sembrando el miedo al rey en sus rivales.

Este tipo de actuaciones de los privados existieron también durante el reinado de Pedro I. En ocasiones las víctimas eran los mismos hermanos del rey, como Enrique y Tello ${ }^{68}$. Los nobles también indicaron al rey cómo tenían "miedo de muerte" por lo que algunos privados "informaban mal" al rey. Es el caso de Juan Alfonso de Alburquerque, que había sido él mismo privado regio, y que no comparecía ante el rey por

${ }^{65}$ Gran Crónica de Alfonso XI, p. 397.

${ }^{66}$ Ferrán Sánchez de Valladolid, Crónica del rey don Alfonso el onceno, p. 220.

67 Ibídem, p. 240.

${ }^{68}$ Estos se disculparon ante el rey de no acudir antes por el temor a lo que los privados regios le decían de ellos: Pero López de Ayala, Crónica del rey don Pedro primero, p. 432. 
ese miedo ${ }^{69}$. Sin duda la mentira tenía unos réditos políticos muy importantes gracias al miedo.

Esto no desapareció en el siglo XV, de nuevo, pues los conflictos y las aspiraciones de poder de la nobleza fueron campo sembrado para este tipo de actuaciones. Así, en 1431, cuando el rey Juan II intentaba recuperar las posesiones de los infantes de Aragón y sus partidarios, no se dudó en utilizar el miedo como forma de conseguir la rendición. Con Alonso Rodríguez de Sepúlveda, alcaide de Castrojeriz por el conde de Castro, se utilizó el miedo y la esperanza de obtener mercedes para conseguir la rendición. El relator regio "le dixo tantas cosas e le puso tantos miedos, e le dio esperanzas de tantas mercedes, que le entregó la fortaleza" ${ }^{\text {"70 }}$.

El miedo, además, siguió siendo una forma de ganarse voluntades. Así, Juan Pacheco no dudó en mentir a Alfonso de Fonseca, arzobispo de Sevilla, para que colaborase con él. Su objetivo era conseguir la expulsión de Isabel y Fernando del reino, y, a decir de la crónica, el arzobispo "seguía el querer del maestre más por miedo que por amor" $"$.

¿Qué podía motivar esta utilización de la mentira como un arma? ¿Por qué buscar sembrar el miedo? La respuesta aparece clara: obtener un rédito político, un beneficio que solía centrarse en el alejamiento del poder de aquél que había sido objeto de este "ataque mentiroso". Se buscaba, sin duda, lograr el enfrentamiento con el poder regio (bien fuese éste ostentado por el rey o por regentes) con aquellos que eran objetivo de la mentira. Esto es algo de lo que se tenía clara consciencia en aquellos momentos, como se ha podido comprobar en el caso de Sancho IV: el objetivo era alejar a alguien del poder regio, enfrentarle a él si era, incluso, posible. Y en muchas ocasiones se logró. Esto, obviamente, respondía a unas aspiraciones de poder propias, que en algunas ocasiones son claramente identificables, como el caso de Fernán Rodríguez, el infante Juan, el infante Enrique, Juan Martínez de Leyva... Quedar en el poder, junto a él y lo más sólo posible, esa es la razón, bien se tratase de una conquista del poder, una defensa o, en ocasiones, una reconquista.

\subsection{CONSECUENCIAS DEL MIEDO EN LA POLÍTICA CASTELLANA}

Tras repasar aunque sea someramente, la casuística de la aparición del miedo como arma en la política castellana podemos presentar al menos las líneas generales de las respuestas a que llevó el miedo, así como las consecuencias que tuvo. Es interesante apreciar cómo en muchas ocasiones el miedo surtió efecto. Sin lugar a dudas era un importante acicate para forzar a la gente a actuar de una forma determinada. En muchos casos hemos visto cómo se consigue que la víctima del ataque huya del rey, es decir, se consigue el objetivo principal: que el miedo al rey lleve a rehuirle. Esto se reflejó de diversas formas: huida de la corte, encastillamiento en las propias

${ }^{69}$ Ibídem, pp. 434-435.

${ }^{70}$ Lorenzo Galíndez de Carvajal, Crónica del serenísimo príncipe don Juan, segundo deste nombre, ed. Cayetano Rosell en las Crónicas de los Reyes de Castilla, vol. 2, Biblioteca de Autores Españoles 68, Madrid: 1953, p. 490.

71 Diego Enríquez del Castillo, Crónica de Enrique IV, ed. Aureliano Sánchez Martín, Valladolid: Universidad de Valladolid, 1994, p. 371. 
fortalezas o villas e, incluso, en algunos casos el exilio. Con ello, en ocasiones, iba aparejado el enfrentamiento con un rey que tomaba tal alejamiento como un síntoma de oposición.

En otras ocasiones el objetivo fracasaba y el que buscaba inculcar el miedo era el que debía afrontar las consecuencias. Lo hemos visto en el caso de los nobles que trataron de utilizarlo para obtener una mayor cercanía al poder regio o para alejar a los rivales. Acababan perdiendo la privanza y en algún caso debiendo dejar la corte. Así, hemos visto cómo Fernán Rodríguez, prior de San Juan, dejó de tener la confianza regia después de su intento de alejar a Juan Manuel alentando el miedo al rey por medio de la mentira ${ }^{72}$. Y lo hemos visto también en casos de nobleza menor, como Nuño González, que dejó la corte humillado por el rey y la nobleza después de haber intentado separar a Juan Núñez de Sancho IV por medio de la mentira ${ }^{73}$.

La misma monarquía sufrió también diversos reveses en su aplicación del miedo como arma. La eliminación de rivales políticos, pese a los actos de índole propagandística que se realizasen, no siempre llevó a una pacificación del reino. Incluso en ocasiones fue todo lo contrario. Las muertes de Juan el Tuerto ${ }^{74}$, Alvar Núñez ${ }^{75}$, Juan Núñez... no supusieron la pacificación de la nobleza. Incluso, bien al contrario, llegaron a acarrear problemas mayores, como el caso de la ejecución de Juan Núñez, que hizo que, por temor, Juan Manuel abandonase la frontera para encastillarse en sus posesiones ${ }^{76}$.

\section{CONCLUSIONES}

Tras un somero repaso a la presencia del miedo en la Baja Edad Media castellana, parece plausible afirmar que efectivamente el miedo se utilizó como un arma política. Hubo acciones encaminadas a imponer el miedo, como recurso político, de forma que se forzase a una o varias personas a actuar de una forma determinada. No se puede dudar de que hubo acciones encaminadas a imponer ese miedo y no sólo por el poder regio, también por parte de otras personas con sus propios intereses que no tenían por qué coincidir con el poder regio y, con ello, con las obras cronísticas redactadas en su entorno. De esta forma, la política del miedo se extiende más allá de la propia construcción política de la monarquía ${ }^{77}$, para inscribirse en el conjunto de los usos políticos como un arma más. No niego que este procedimiento pudiese partir de la monarquía, o que sea la plasmación cronística, como fenómeno constructor o reconstructor de una evolución política, pero parece claro que, como otro tipo de fenómenos políticos bajomedievales, también pasó a ser utilizado por la nobleza.

${ }^{72}$ Ferrán Sánchez de Valladolid, Crónica del rey don Alfonso el onceno, p. 220.

73 Ferrán Sánchez de Valladolid, Crónica del rey don Sancho IV, p. 84.

${ }^{74}$ Ferrán Sánchez de Valladolid, Crónica del rey don Alfonso el onceno, p. 202.

75 Ibídem, p. 219.

${ }^{76}$ Ibídem, p. 163.

77 Este uso, como forma de llevar a una negociación y un acuerdo o pacto, fue presentado ya por François Foronda, "El miedo al rey. Fuentes y primeras reflexiones acerca de una emoción aristocrática en la Castilla del siglo XIV", e-Spania, 4 (2007) [consultado por última vez el 27 de diciembre de 2012], URL : http://espania.revues.org/2273; DOI: 10.4000/e-spania.2273, §. 18. 
Sea como fuere, y más allá de la interpretación del miedo como sentimiento, parece plausible establecer que esta utilización del miedo tenía unos objetivos concretos en cada momento, pero que pueden ser diversos por la diversidad de situaciones. En general, podríamos aceptar que se busca alejar a un rival del entorno del poder, o forzar a este a tomar una acción determinada que favorece los intereses propios. De lo que no parece caber duda alguna es de que se buscaba amedrentar a los rivales. Es decir, había un objetivo claro: sembrar el miedo, lo que Foronda ha llamado la "política del espanto" y yo llamo la política del miedo ${ }^{78}$. Había una intención concreta y, por ello, una política intencionada del miedo.

Hay notables diferencias, obviamente, en cuanto a los medios empleados, pues no todos los actores políticos tenían a su disposición las mismas herramientas. Hay que distinguir claramente los de la nobleza de aquellos que utilizó el poder regio.

La nobleza recurre de forma repetida a la sublevación, a la amenaza y, en ocasiones, a la mentira. El poder regio se podía ver amedrentado por la amenaza y por las armas, y de esta forma se buscaba obtener un rédito político. Esas mismas armas la nobleza podía utilizarla contra miembros de sus propias filas, pero el que fue, aparentemente, más rentable fue la utilización de la mentira. Mentir en los oídos del rey para enfrentarle con un noble, o en los oídos del noble para que sintiese miedo de la acción regia, tuvo unos resultados mucho más efectivos.

La monarquía, sin embargo, tenía unos medios mucho más diversos. Por un lado aquellos que compartía con la nobleza: la utilización de la fuerza, de la amenaza y, en ocasiones, también de la mentira. Pero por otro lado había otros recursos que le eran propios y exclusivos: la utilización de la ley y de las formas legales. Los monarcas del siglo XIV y del XV no dudaron en utilizar al poder que las leyes aplicables les otorgaban en caso de traición. Acciones como el juicio a cadáveres, o la sentencia a muerte de nobles denunciados como traidores les enmarcaban en el conjunto de la ley (incluso en el caso de los juicios póstumos) ${ }^{79}$. Si a esto unimos la utilización de todos los recursos que la propaganda (aunque fuese escasa) ponía a su disposición, parece plausible indicar que su capacidad de extender el miedo era mucho mayor que la de la nobleza.

De esta forma la utilización de los actos simbólicos y públicos por parte de la monarquía como una forma de magnificar los efectos de la política del miedo, se nos presenta como algo cierto y real. La utilización de juicios más o menos públicos, del pregón de las sentencias, y de las fórmulas utilizados en estos (la mención del delito de traición, la ejecución infamante...) nos muestran esa intención ejemplarizante que era fundamental para, aunque fuese por el miedo, lograr unos objetivos concretos.

\footnotetext{
78 Ibídem, § 5, 7-11.

${ }^{79}$ Las Siete Partidas, VII, II, 2: "Et esta trayción es de tal natura que maguer muerta el que la fizo ante que sea acusado, puédenlo acusar aun después de su muerte, et si su heredero non lo pudiere defender o salvar con derecho, debe el rey judgar al muerto por enfamado de trayción, et mandar tomar a su heredero todos los bienes quel vinieron de parte del traydor".
} 